\title{
UM ESTUDO SOBRE A INSERÇÃO DAS PRÁTICAS MATEMÁTICAS HISTÓRICAS POR MEIO DE UBP NO ENSINO DE MATEMÁTICA
}

\section{A STUDY ON THE INSERTION OF HISTORICAL MATHEMATICAL PRACTICES THROUGH UBP IN MATHEMATICS EDUCATION}

\author{
Marina Oliveira Tavares ${ }^{1}$ \\ Universidade Estadual do Ceará - UECE \\ Ana Carolina Costa Pereira ${ }^{2}$ \\ Universidade Estadual do Ceará - UECE
}

\begin{abstract}
Resumo
A Unidade Básica de Problematização - UBP, que é um flash de memória discursiva, descreve uma prática sociocultural num campo da atividade humana e, por algum motivo, é eleito como um objeto de problematização disciplinar. A UBP faz parte do quadro de metodologias ativas, e por meio de atividades de investigação proporciona o desenvolvimento do aluno com uma aprendizagem ativa, oferecendo a ele uma autonomia no aprendizado na construção do seu conhecimento em sala de aula. Nesse processo, o professor está inserido e se compromete com o aprendizado do aluno, estimulando e permitindo a discussão entre os mesmos, conduzindo-os apenas se necessário, ao passo que os alunos examinam e refletem sobre a historicidade e cultura matemática propostas, realizando assim o exercício do pensar. Nesse artigo além de realizarmos um estudo sobre a inserção das práticas matemáticas históricas no ensino, apresentaremos também uma proposta de UBP no intuito de proporcionar um recurso com futura aplicação em sala de aula. Dessa forma, essa pesquisa proporciona aos professores outra possibilidade metodológica que pode ser aplicada em qualquer nível de ensino, trazendo uma melhoria na aprendizagem dos alunos nas aulas de matemática.
\end{abstract}

Palavras-chave: História da Matemática; Educação matemática; Práticas matemáticas históricas; Unidade Básica de Problematização - UBP.

\begin{abstract}
The Basic Unit Problematization - UBP, which is a flash of discursive memory, describes a socio-cultural practice in a field of the human activity and, for some reason, is elected as a disciplinary questioning object. The UBP is part of the framework of active methodologies, and through research activities provides the development of students with an active learning, offering him an autonomy in the learning and in the construction of the knowledge in the classroom. In this process, the teacher is inserted and is committed to student learning, stimulating and enabling discussion among them,
\end{abstract}

\footnotetext{
${ }^{1}$ E-mail: marina.oliveira@aluno.uece.br

22E-mail: carolina.pereira@uece.br
} 
leading them only if necessary, while the students examine and reflect on the historicity and mathematical culture proposals, performing the exercise of thinking. In this article, in addition to make a study on the inclusion of historical mathematical practices in education, we also present a proposal for UBP in order to provide a resource with future application in the classroom. Therefore, this research gives to the teachers another methodological possibility that can be applied at any education level, bringing an improvement in student learning in math classes.

Keywords: History of Mathematics; mathematics education; historical mathematical practice; Basic unit Problematization - UBP.

\section{Introdução}

Estudos e pesquisas feitos na área de Educação Matemática têm buscado elementos que agreguem valores ao ensino, para que haja uma superação nas dificuldades encontradas nas salas de aula. Métodos que mostram a Matemática de uma forma interdisciplinar tem sido o foco dessas pesquisas, sendo desenvolvidos meios que agreguem objetos do cotidiano e de outras disciplinas nas aulas de matemática, de modo a enriquecer a prática pedagógica.

Durante o século XX, as aulas expositivas significavam uma aula tradicional, onde o conhecimento era transmitido do professor para o aluno, de forma que foi muito criticada pelos educadores. Entretanto, uma aula expositiva bem planejada e realizada pode ser um meio para ensinar certos conteúdos, mas este recurso ao pode ser o único utilizado nas aulas de matemática.

O uso de materiais manipulativos, jogos, Modelagem Matemática ou mesmo da EtnoMatemática são aportes que contribuem para uma melhor aprendizagem e estimulam o fortalecimento da Matemática como uma disciplina dinâmica que tem espaço para a criatividade em sala de aula.

Nesse sentido, o professor deve utilizar outros meios em suas aulas de matemática, pois ele tem extrema importância no processo educativo, pois ao contrário, acabará perdendo seu espaço na educação. A seguir, D’Ambrósio (1996) esclarece essa ideia.

\footnotetext{
O professor que insistir no seu papel de fonte e transmissor de conhecimento está fadado a ser dispensado pelos alunos, pela escola e pela sociedade em geral. O novo papel do professor será o de gerenciar, de facilitar o processo de aprendizagem e, naturalmente, de interagir com o aluno na produção e crítica de novos conhecimentos (...) (D'AMBROSIO, 1996, p. 79-80).
}

Com a finalidade de trazer melhorias no aprendizado matemático, consideramos a utilização de Unidades Básicas de Problematização (UBP) uma proposta que, se 
empregada de forma correta, pode agregar valores e tornar as aulas de Matemática dinâmicas e instigantes.

A UBP é um flash discursivo memorialístico de uma prática social, descrito por Miguel e Mendes (2010), da seguinte forma:

Um flash discursivo memorialístico que descreve uma prática social situada em um determinado campo de atividade humana, essa teria sido de fato realizada para se responder a uma necessidade (ou desejo) que teria se manifestado por um ou mais dessa comunidade de prática, em algum momento do processo de desenvolvimento dessa atividade humana. (MENDES; MIGUEL, 2010, p. 386) (Tradução nossa).

E tal prática pode ter diferentes significados dependendo da comunidade e situação que será aplicada, mobilizando diferentes fins, instrumentos, métodos e objetos culturais dessa comunidade. Miguel e Mendes (2010) caracterizam práticas sociais e citam um exemplo a seguir de diferentes contextos de utilização da prática citada:

\begin{abstract}
No entanto, uma prática não é sempre uma atividade, uma vez que a prática pode ser realizada em diferentes atividades, tendo em diferentes significados em função das diferentes finalidades que orientam o seu desempenho em diferentes atividades. Poderíamos, por exemplo, realizar a prática de mãos que aplaudem em uma festa de aniversário, para saudar o celebrante aniversário, ou na porta de uma casa sem uma campainha para chamar para seus habitantes, ou dentro de uma sala de aula para chamar a atenção dos alunos, ou mesmo aplaudindo um artista num concerto, bem como em muitas outras situações. E em cada um deles, a prática de " bater palmas " tem um significado diferente. (MENDES; MIGUEL, 2010, p. 383) (Tradução nossa).
\end{abstract}

A partir das práticas socioculturais matemáticas encontradas ao longo da história, são confeccionadas as UBPs, onde os alunos terão a autonomia de discutir e resolver as atividades propostas, construindo assim o seu conhecimento e desenvolvendo o ato do pensar. Elas são caracterizadas por um conjunto de problematizações investigadas. Neste caso, estas investigações são feitas com o objetivo metodológico para as aulas de matemática, por isso, práticas de mobilização de cultura matemática são o objeto dessas investigações. São práticas realizadas por comunidades em diferentes atividades humanas. O termo aqui abordado é visto como um conjunto de ações, e não apenas uma, que podem ser realizadas em diferentes contextos. Daí também vem à ideia que podemos trazer uma, ou várias práticas passadas, para o presente, e ainda assim preservar a memória daquela prática.

Trabalhos de alguns pesquisadores (SOARES, 2011; LIMA FILHO, 2013; PEREIRA, 2014), já trazem propostas de UBP envolvendo o Ensino de Matemática, entretanto à construção e aplicação de UBP ainda estão em crescimento. 
Neste artigo, estudaremos sobre como a proposta de UBP contribui no processo de aprendizado de forma significativa as aulas de matemática, bem como algumas orientações quanto à aplicação em sala de aula.

\title{
A Unidade Básica de Problematização
}

A confecção de UBP a partir das práticas históricas de cultura matemática para o ensino tem por objetivo contribuir na formação dos professores com uma proposta que enfatiza a participação do aluno no processo de aprendizagem dando-lhe autonomia na aquisição e construção de seu conhecimento matemático com um pensar crítico e reflexivo. Logo, a inserção das UBPs no ensino de matemática contribui para a construção de significados conceituais ${ }^{3}$ e metacognitivos ${ }^{4}$ ao trazerem soluções criativas para cada problematização proposta. Isso se torna claro quando Lima Filho (2013) discute:

\begin{abstract}
Elas são exclusivamente produzidas com o propósito de se problematizar práticas escolares de mobilização de cultura matemática contrastando-as com modos como cultura matemática poderia ter sido e/ou é constituída ou mobilizada em outras atividades humanas. Isso não significa, porém, que essas UBPs não pudessem ser modificadas e utilizadas, com outros propósitos, sobretudo, junto aos próprios estudantes do Ensino Fundamental ou Médio. É por essa razão que grande parte das UBPs não exige um conhecimento matemático muito elaborado para serem inicialmente discutidas em aula, embora a problematização de uma UBP, devido a sua natureza sempre aberta e indisciplinar, possa atingir níveis imprevistos de profundidade, sofisticação, complexidade, sutileza e originalidade. (LIMA FILHO, 2013, p.24).
\end{abstract}

Propostas de UBPs podem ser utilizadas em diferentes níveis de ensino, onde o professor tem a liberdade de trabalhar com objetos históricos e culturais de acordo com a comunidade que seus alunos estiverem inseridos. Dessa forma, ao inserir elementos socioculturais e no ensino da matemática, o aluno enxergará a matemática de forma completa, tendo em vista uma contribuição no processo de ensino e aprendizagem.

Miguel e Mendes (2010) baseiam a UBP na proposta de aprendizagem expansiva de Engeström (1991). A autora sugere a utilização de novas formas de aprendizagem, não somente a metodologia expositiva, mas propostas que incentiva os alunos a refletirem, sendo o professor a figura que estimula e permite o desenvolvimento dos

\footnotetext{
${ }^{3}$ Conceituais: formulação de uma ideia por palavras;

${ }^{4}$ Metacognitivos: uso de habilidades estruturantes para o processo de aprendizagem desta ideia;
} 
alunos, oportunizando a aprendizagem durante as discussões sobre a historicidade e a cultura matemática.

A UBP não descarta a utilização de livros didáticos em sala de aula, pois ela complementa a abordagem didática dos conteúdos inseridos nos livros com os aspectos históricos e socioculturais, bem como princípios aprendidos pelos alunos, de forma a trazer melhorias no aprendizado. Nesse sentido, o uso da história é feito para que o aluno associe o conhecimento da matemática com as suas aplicações percebendo-a como uma criação humana, incentivando-o assim a buscar razões pelas quais ela é feita. Ao enxergar as conexões com outras áreas de conhecimento, o aluno consegue ver a matemática como uma criação humana.

Por ser uma metodologia ativa, a UBP está atrelada ao trabalho colaborativo promovendo o desenvolvimento de estudo em grupo e individual no ritmo de cada aluno, sendo o professor mediador desse desenvolvimento. Dessa forma, as atividades investigativas inseridas nas UBPs trazem ao aluno a autonomia de desenvolver seus estudos, de forma a construir seu próprio conhecimento, buscando na sua própria experiência a compreensão e explicação própria sobre o mundo. Logo, a UBP trás uma significação maior ao aprendizado dos conteúdos matemáticos que os exercícios tradicionais, pelo fato de estarem embasados a uma relação histórica e social, que são elementos importantes neste processo de aprendizado.

\section{Uma proposta para a sala de aula}

A UBP que estamos propondo nesse artigo foi construída durante a nossa pesquisa a partir das práticas socioculturais matemática inseridas na obra Ex ludi rerum mathematicarum (Matemática Lúdica) de Leon Battista Alberti de 1452. O motivo de escolhermos tal trabalho foi pelo fato de a obra já estar traduzida para o português, poupando assim o tempo de tradução.

Além disso, a obra de Alberti (2006) trás procedimentos notáveis para a resolução de problemas práticos de todos os tipos, oferecendo a facilidade no entendimento destas resoluções ao utilizar uma geometria que se chamava de geometria practica, com procedimentos bastante óbvios para o leitor moderno e com uma simples compreensão, sem demonstrações e fundamentada por exemplos numéricos. Observamos também a simplicidade na prática destas resoluções, onde desperta no leitor o interesse e curiosidade de praticar tais métodos mencionados no livro. 
Ressaltamos que a UBP proposta nesse artigo pode ser lapidada para uma futura aplicação em sala de aula. Apenas estamos retratando uma ideia de como são formulados os questionamentos em uma UBP e de que forma podemos trazer esse convite ao ato do pensar para a sala de aula de forma lúdica, instigante e divertida.

\section{UBP: Medir o tempo através dos movimentos da Terra pela direção Sul.}

Introdução: Nesta UBP criada a partir da problematização histórica sobre medição de tempo pelo movimento do Sol e das estrelas, convidamos os alunos ao ato do pensar com relação à medição do tempo com vários tipos de relógios (astrolábio, quadrante solar, esferas armilares e aneis portáteis), a partir de uma prática que determina o lado Sul como referência.

Conteúdos: Geometria da circunferência.

Objetivos: Utilizar os conceitos geométricos sobre o círculo para determinar a região Sul, que é de onde iremos medir o tempo a partir dos movimentos da Terra.

Público-alvo: Alunos do ensino fundamental II.

Metodologia: Estruturada pelas propostas de UBP.

Problematização histórica: Alberti (2006) descreve em sua obra uma maneira de descobrir a direção Sul de onde estamos, pois se acredita que esta é a melhor maneira para medir o tempo com o astrolábio, quadrante solar, esferas armilares, entre outros. A seguir, temos a descrição do método utilizado por Alberti.

\footnotetext{
Se portanto quiser encontrar a direção sul num lugar qualquer, fará como se segue. Finque bem reto sua flecha num local plano, certifique-se de que permaneça em posição bem vertical, como disse antes, depois, entre o almoço e meio-dia, pegue um barbante, amarre na base da flecha, corte-o justamente no lugar em que termina a sombra da flecha sobre o solo e, girando, faça no chão um círculo em torno dessa flecha. A ponta da flecha fincada será, portanto o centro desse círculo, que chamaremos de A. Chamemos B o lugar em que a extremidade da sombra da flecha cai precisamente sobre o círculo. Deixe a flecha como está. Enfie um pedaço de madeira no ponto B. volte uma hora mais tarde; verá que a sombra da flecha encontra-se em outro ponto. Espere que venha tocar precisamente o círculo e marque com outro pedaço de madeira o lugar, que estará mais perto do lado onde o Sol nasce; chamemos C essa marca, como podemos ver na figura 5.
} 


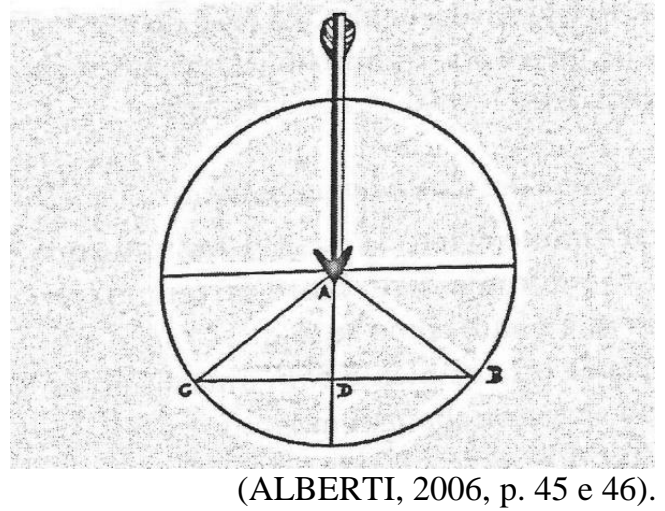

Marque entre a reta $\mathrm{BC}$ um ponto médio, chamaremos este ponte de $\mathrm{D}$. Trace outra reta de A até o ponto D. Esta reta estará dirigida para o sul do lugar onde estiver. A partir desta informação os instrumentos de medição de tempo irão ser instalados corretamente.

Para obter as mesmas informações no período noturno teremos que ter a estrela polar como referência. Poderemos localizá-la da seguinte forma: acima de qualquer arvora, torre, monumento, ou qualquer outra coisa desse tipo ela estará nesta posição. Quando a encontrar cercada por outras estrelas, escolha a maior dessas e a tenha como referência também. Ela voltará para a mesma posição passada às 24 horas e gira em torno da estrela Polar.

Observe que parte do círculo ela percorreu. Se for $1 / 4$ do círculo 6 horas terão se passado; se for 1/3 do círculo serão então 8 horas, e assim por diante. Segundo Alberti (2006; p. 47), há um meio de encontrar a estrela Polar. “(...) Se traçar com o olhar, uma reta passando pelas duas estrelas maiores que se encontram por trás dessa configuração estelar, dará na passagem com uma estrela, não pequena mas tampouco muito grande. Essa primeira estrela será precisamente aquela que está buscando e dista das duas estrelas mencionadas algo como 4 vezes a distância de uma a outra."

\section{Construção do Relógio de sol}

Inicialmente iremos falar sobre a construção de um relógio de sol para realizarmos a Problematização proposta. Ilustraremos uma forma bastante simples de confecção deste instrumento para facilitar a aplicação e discussão dos principais temas desta UBP. Portanto, iremos necessitar de alguns materiais:

1. Cartolina de cor clara;

2. Tesoura; 
3. Transferidor;

4. Régua;

5. Pincel azul ou preto.

Tome uma folha de cartolina de cor clara, mas que seja firme. Tome o transferidor e trace uma semicircunferência, trace partindo do ponto inicial e final o diâmetro $\mathrm{AB}$ (figura 1), dividindo a semicircunferência em 14 partes iguais. Marque da direita para esquerda as horas, iniciando de 6 horas até às 18 horas.

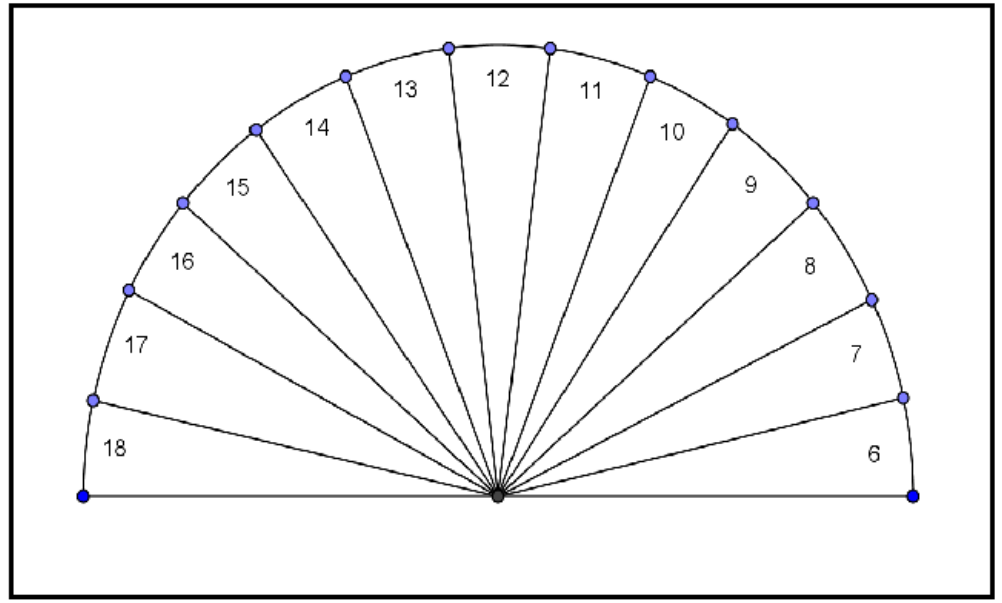

Figura 1: Etapa 1 do processo de construção do relógio Fonte: Elaboração nossa

Em seguida, recorte a semicircunferência e com o que sobrou da cartolina faça um ponteiro para o relógio. Corte um pouco do centro da semicircunferência e coloque o ponteiro (figura 2). Realizado todo este processo teremos o nosso relógio de Sol para concluirmos o projeto da problematização.

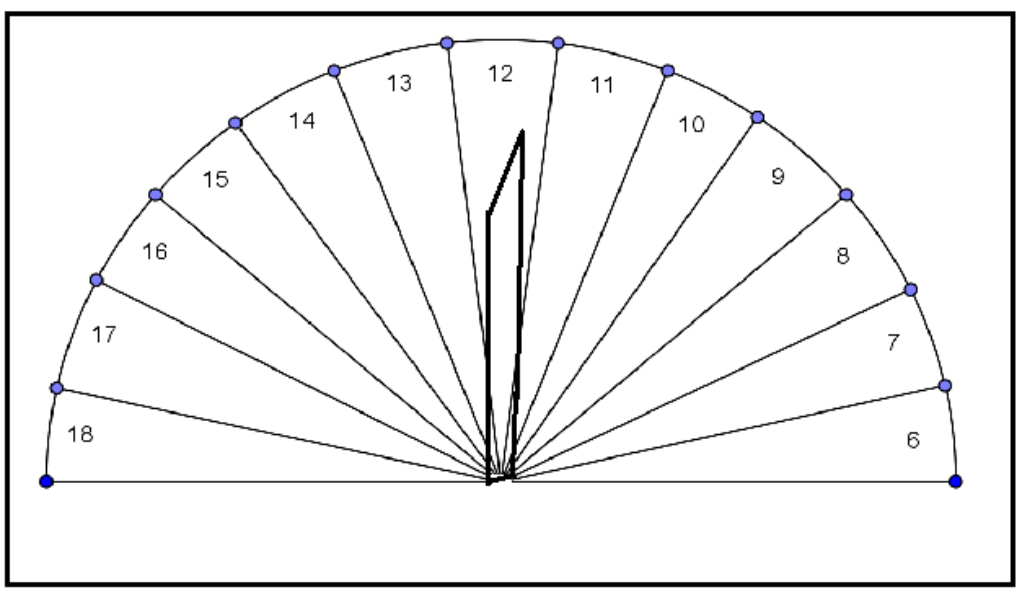

Figura 2: Finalização do relógio de sol.

Fonte: Elaboração nossa. 
Problematização: Os professores de Ciências e Matemática de uma escola reuniram-se e criaram um projeto interdisciplinar onde, os alunos iriam criar um meio de medir o tempo a partir de um instrumento que eles criaram. Para realizar tal propósito precisariam determinar qual a direção sul na escola. Suponha que você, discente, esteja neste projeto. A partir da prática descrita por Alberti, realize com seus colegas e professores o método proposto para indicar a direção Sul e conseguir atingir o propósito de seu projeto escolar. Lembrando que no lugar da flecha irá ser utilizando uma vara.

Analisando a problematização, faremos os seguintes questionamentos:

1. A prática sociocultural descrita por Alberti (2006) é adequada para encontrarmos a direção Sul e em seguida utilizarmos o relógio de Sol? Por quê?

2. Os relógios são utilizados para a medição de tempo desde a Antiguidade, sendo o relógio de Sol o mais antigo. Para uma melhor reflexão sobre eles, descreva alguns relógios mais utilizados desse período até hoje e como utilizavam cada um deles

3. Atualmente dispomos de muita tecnologia para realização da medição do tempo. Dessa forma, cite os artefatos tecnológicos que poderiam nos auxiliar neste trabalho e de que forma poderíamos utilizá-lo. Com o auxilio deles, teríamos uma forma mais simples de encontrar a informação desejada? Por quê?

4. Quem foi Leon Battista Alberti e por quais motivos teria construído o método apresentado?

5. Ao realizar o procedimento meça quantos centímetros tem a sombra formada pela vara. Sabendo destes dados, qual informação você terá do círculo?

6. A partir dos dados da sombra da vara, qual será a distância entre um pedaço de madeira até o outro? Qual a distância em $\mathrm{cm}$ do ponto médio até as extremidades do círculo?

7. O que significam, matematicamente, cada informação encontrada após o experimento?

8. De acordo com as informações, calcule agora a área do círculo formado.

\section{Orientações sobre a aplicação da UBP em sala de aula}


Miguel e Mendes (2010) trazem algumas orientações quanto à inserção das UBPs em sala de aula. Os participantes se dividirão em grupos para iniciarem uma leitura e discussão em grupo sobre os textos disponibilizados pelo professor sobre a prática sociocultural histórica para depois refletirem sobre as práticas propostas na UBP.

Divididos em grupo nós oferecemos a problematização histórica para a discussão e realização, sem mencionar os conteúdos matemáticos existentes nela. Nessa etapa pode ser disponibilizado aos alunos o que for necessário para a reflexão do assunto proposto, bem como material para a produção de algum instrumento. À medida que os participantes se envolvem, fazem também levantamentos que podem levar a outras problematizações.

Terminado esse processo iremos fazer uma sessão de problematização coletiva, onde cada grupo irá escolher um representante que vai expor as ideias do grupo. Esse processo é interessante, pois na medida em que expressam as discussões em grupo, novas ideias são geradas e diversas soluções criativas são encontradas.

Logo em seguida de forma individual eles irão realizar a atividade, e depois se dividirão em grupos novamente para discussões e começam a colocar em textos o que refletiu de forma individual sobre as práticas históricas e as problematizações. Depois irão expor em uma apresentação, explanando as memórias que haviam refletido antes, abrindo para novas discussões. Nesse momento percebe-se a diversidade de soluções criativas encontradas pelos alunos, de forma que algumas vezes superam as expectativas do professor. Ressaltamos que dependendo das discussões, a fase de retornar aos grupos para mais reflexões pode ser repetida quantas vezes for necessário.

Terminado esse processo, os alunos retornam aos grupos. Nessa fase o professor disponibiliza os questionamentos propostos na UBP e um conjunto de referências para auxiliar a resolução. Para a realização desse processo eles irão utilizar o que refletiram acerca do assunto, e se possível, realizar mais pesquisas para solucionar o bloco de atividades investigativas.

$\mathrm{Na}$ medida em que resolvem cada questionamento, eles se recordam dos conteúdos matemáticos aprendidos em sala de aula, de forma que os conceitos tratados em sala de aula passam a ter uma significação maior o aprendizado. Logo, a UBP trás por meio das atividades de investigação a possibilidade de respostas dos muitos "porquês" presentes em sala de aula. 
De acordo com Miguel e Mendes (2010), na aplicação de UBP percebe-se que quanto mais fontes históricas, mais discussões os alunos farão de diferentes formas. Por exemplo, sobre a cultura matemática de certo tempo até o atual, sobre instrumentos antigos e suas relações com os atuais e entre outros assuntos que podem ser gerados nas discussões. De forma que sempre estarão criando linhas discursivas diferentes.

\section{Considerações finais}

A proposta de produção de UBP na formação de professores de matemática pode ser uma opção didática que possibilita um melhor aproveitamento do processo de ensino e aprendizagem de matemática por trabalhar de maneira agradável e instigante os conteúdos matemáticos com a finalidade de que a Educação Básica realmente forme o aluno tornando-o crítico e agente ativo na transformação da sociedade.

Propostas de UBPs por meio das atividades investigativas trazem essas possibilidades de aprendizado a partir da investigação em História da Matemática trazendo melhorias no ensino a partir de um estudo histórico epistemológico dos conteúdos matemáticos, de forma a explicar os "porquês" existentes os conteúdos matemáticos escolares.

Além disso, torna o aluno importante nesse processo de aprendizagem, não apenas como um mero ouvinte, pois lhe oferece a oportunidade de construir seu conhecimento em sala através de cada discussão proposta e pesquisas realizadas durante as problematizações, incentivando assim ao pensar crítico e reflexivo sobre cada aprendizado que ele desenvolver.

A proposta de UBP dá ao professor uma liberdade de aplicação dentro ou fora de sala de aula, para que os alunos não enxerguem a matemática de forma isolada e abstrata, mas sim como uma disciplina que permite pesquisar e criar de diversas formas, promovendo ao aluno aulas mais dinâmicas e divertidas. Portanto através desse artigo estamos oferecendo ao professor uma proposta a ser utilizada por ele em suas aulas de matemática, melhorando e facilitando o processo de aprendizagem matemática.

\section{Referências}

ALBERTI, Leon Battista. Matemática Lúdica. Edição apresentada e comentada por Pierre Souffrin. Tradução de André Telles. - Rio de Janeiro: Jorge Zahar, 2006. 
D’AMBROSIO, Ubiratan. Educação Matemática: Da teoria à prática. Coleção Perspectivas em Educação Matemática - Campinas, SP: Papirus, 1996.

LIMA FILHO, Renato Rodrigues Cunha. Um Estudo de Práticas Matemáticas Históricas e Sugestões de uso na Matemática Escolar. Dissertação (Mestrado em Ensino de Ciências Naturais e Matemática) - Universidade Federal do Rio Grande do Norte, 2013.

MIGUEL, Antonio; MENDES, Iran Abreu. Mobilizing histories in mathematics teacher education: memories, social practices, and discursive games. In: ZDM Mathematics Education, n. 42, p. 381-392, 2010.

PEREIRA, Daniele Esteves. Correspondências Científicas como uma relação didática entre História e Ensino de Matemática: $O$ exemplo das Cartas de Euler a uma Princesa da Alemanha. Tese (Doutorado em Educação) - Universidade Federal do Rio Grande do Norte, 2014.

SOARES, Evanildo Costa. Uma Investigação Histórica sobre os logaritmos com sugestões didáticas para a sala de aula. Dissertação (Mestrado em Ensino de Ciências Naturais e Matemática) - Universidade Federal do Rio Grande do Norte, 2011. 